\title{
Mengurangi Antrean pada Stasiun Pengisian Bahan Bakar Umum dengan Pendekatan Simulasi Menggunakan ProModel
}

\section{Reducing Queues at Gas Station with Simulation Approach Using ProModel}

\author{
Mirna Lusiani $^{1 *}$, Anie Belita ${ }^{1}$ \\ ${ }^{1}$ Program Studi Teknik Industri, Universitas Bunda Mulia, Jl. Lodan Raya No. 2 Ancol, Jakarta Utara 14430, \\ Indonesia
}

Diterima: 8 Desember, 2018 / Disetujui: 16 Februari, 2019

\begin{abstract}
The gas station has become an important facility for the public, especially for people in large cities such as Jakarta. This condition was caused by increasing demand from year to year. The number of facilities has less number than the customer that came, which could cause queueing in the station. This research was made with the purpose to reduce the number of the queue and increase the number of customers serviced at the gas station. This research located on one of the gas stations in Jakarta at 16.00-18.00 from Monday to Friday. The data used for this research is primary data which was observed directly by the researcher. The data used for this research are the number of customers arrived and service time. Data analysis is using discrete-event simulation with ProModel software. The conclusion of this research is the actual system has a relatively high number of queueing customer which also affect the reduced number of customers that was served. Improvement model was created by decreasing the service time by $10 \%$ with the average number of queues by 4 customers for Pertalite and 4 customers for Premium. Scenario model is also designed as a proposal by using customer migration scenario from Premium to Pertalite by 30\%, 60\%, and 100\%. The proposed system for the first scenario is by decreasing the service time by $20 \%$ with the average number of queues by 8 customers for Pertalite and 1 customer for Premium. For the second scenario is by modifying the queueing system and decreasing the service time by $10 \%$ with the average number of queues by 8 customers for Pertalite and 7 customers for Premium. For the third scenario is by opening a new server for Pertalite with the average number of queues by 5 customers.
\end{abstract}

Keywords: Discrete-event simulation, Queue, Gas station

\begin{abstract}
ABSTRAK
Stasiun Pengisian Bahan Bakar Umum (SPBU) menjadi sarana yang penting bagi masyarakat saat ini terutama di kota-kota besar seperti Jakarta, hal ini disebabkan permintaan masyarakat terhadap Bahan Bakar Minyak (BBM) yang terus meningkat dari tahun ke tahun. Terbatasnya fasilitas layanan SPBU tidak sebanding dengan konsumen yang datang dapat menyebabkan antrean. Maka dari itu, penelitian ini dilakukan dengan tujuan untuk meminimalkan jumlah antrean di SPBU. Penelitian ini bertempat di salah satu SPBU di Jakarta pada pukul 16.0018.00 untuk hari Senin sampai Jumat. Data yang digunakan merupakan data primer yang diobservasi langsung oleh peneliti yaitu data jumlah konsumen dan waktu pelayanan. Pengolahan data menggunakan simulasi diskret dengan menggunakan perangkat lunak ProModel. Hasil dari penelitian ini, dapat diketahui bahwa sistem aktual memiliki jumlah antrean yang relatif tinggi yang juga menyebabkan jumlah konsumen yang dilayani tidak maksimal. Tindakan perbaikan dilakukan dengan mengurangi waktu pelayanan sebesar $10 \%$ dengan rata-rata antrean sebesar 4 orang untuk jenis Pertalite dan 4 orang untuk jenis Premium. Model skenario yang digunakan adalah perpindahan jumlah konsumen dari Premium ke Pertalite sebesar 30\%, 60\%, dan 100\%. Sistem yang diusulkan untuk skenario pertama adalah dengan mengurangi waktu pelayanan sebesar $20 \%$ dengan rata-rata antrean sebesar 8 orang untuk Pertalite dan 1 orang untuk Premium. Untuk skenario kedua adalah dengan cara memodifikasi sistem antrean dengan menggunakan multi-product server serta mengurangi waktu pelayanan sebesar 10\% dengan rata-rata antrean sebesar 8 orang untuk Pertalite dan 7 orang untuk Premium. Untuk skenario ketiga adalah dengan cara membuka satu buah server Pertalite dengan rata-rata antrean sebesar 5 orang.
\end{abstract}

Kata Kunci: Simulasi diskret, Antrean, Stasiun Pengisian Bahan Bakar Umum

*email: mirna_lusiani@yahoo.com 


\section{PENDAHULUAN}

Populasi manusia yang terus meningkat setiap tahunnya (Badan Pusat Statistik Provinsi DKI Jakarta, 2015) menyebabkan jumlah kendaraan semakin meningkat. Oleh karena itu, permintaan pasar akan bahan bakar kendaraan bermotor yang juga ikut meningkat. Stasiun Pengisian Bahan Bakar Umum (SPBU) menjadi sarana yang penting bagi masyarakat saat ini terutama di kota-kota besar seperti Jakarta. Hal ini disebabkan permintaan masyarakat terhadap Bahan Bakar Minyak (BBM) yang terus meningkat dari tahun ke tahun. Meningkatnya kebutuhan masyarakat akan BBM ditentukan oleh beberapa faktor, salah satunya yaitu perkembangan penduduk (Adipraesetya, Sukmaaji dan Taufik, 2014). Terbatasnya fasilitas layanan di SPBU yang tidak sebanding dengan konsumen yang datang dapat menyebabkan antrean. Antrean konsumen dapat berdampak negatif bagi manajemen dari penyedia jasa pelayanan dikarenakan dapat menyebabkan konsumen pergi dan meninggalkan tempat tersebut (Nsude, ElemUche dan Uwabunkonye, 2017). Maka dari itu, penelitian ini dilakukan dengan tujuan untuk meminimalkan jumlah antrean di SPBU.

Penelitian ini bertujuan untuk menganalisis kinerja dari model sistem aktual yang terjadi di SPBU Pangeran Jayakarta. Pada penelitian ini terdapat skenario usulan perpindahan konsumen Premium ke Pertalite.

Penelitian ini dilakukan di SPBU 34.107.02 yang berlokasi di Pangeran Jayakarta. Penelitian ini hanya dilakukan pada pelayanan bahan bakar jenis Pertalite dan Premium untuk kendaraan beroda dua. Jika dalam antrean terjadi penolakan (pengendara keluar dari sistem antrean dan pergi) diabaikan. Data yang diambil yaitu Hari Senin sampai Jumat dari Pukul 16.00 sampai 18.00 .

\section{METODOLOGI}

Objek yang dibahas dalam penelitian ini terbatas hanya pada sistem pengisian bahan bakar kendaraan roda dua untuk jenis bahan bakar Premium dan Pertalite di SPBU Pangeran Jayakarta yang berlokasi di Jakarta Pusat. Pengamatan dilakukan pada pukul 16.00-18.00. Hal yang mendorong peneliti untuk melakukan penelitian di tempat ini adalah karena jumlah antrean kendaraan roda dua di SPBU tersebut pada saat peak hour melebihi standar yang diterapkan pada SPBU tersebut, sehingga menyebabkan tingginya jumlah antrean pada jam tersebut. Tingginya jumlah antrean di SPBU dapat menyebabkan konsumen yang baru datang lebih memilih untuk mencari SPBU lain yang lebih sepi agar lebih cepat terlayani. Maka dari itu, tindakan perbaikan perlu dilakukan untuk meminimalkan antrean dan juga meningkatkan jumlah konsumen yang dapat terlayani. Data yang digunakan dalam penelitian ini adalah data primer. Pengumpulan data primer diperoleh secara langsung oleh peneliti di lokasi penelitian dengan observasi dan wawancara terhadap karyawan SPBU. Data yang digunakan dalam penelitian ini adalah tingkat kedatangan konsumen kendaraan roda dua untuk jenis bahan bakar Premium dan Pertalite, dan waktu pelayanan.

\section{HASIL DAN PEMBAHASAN}

\subsection{Hasil Pengumpulan Data}

1. Tingkat Kedatangan Konsumen

Jumlah rata-rata konsumen Pertalite sebanyak 354,07 orang sedangkan jumlah rata-rata konsumen Premium sebanyak 177 orang, seperti ditampilkan pada Tabel 1. Data kedatangan konsumen lalu dikonversi menjadi waktu antar kedatangan dengan cara membagi waktu observasi yang telah ditentukan dengan total penumpang seperti yang dijelaskan dalam persamaan (1).

Frekuensi kedatangan

$$
=\frac{7200 \text { detik }}{\text { Jumlah konsumen }}
$$

Tabel 1. Data Hasil Pengamatan Kedatangan Konsumen (orang)

\begin{tabular}{lcc}
\hline Hari & Pertalite & Premium \\
\hline Rata-rata & 354,07 & 177,00 \\
Stdev & 18,92 & 12,59 \\
\hline
\end{tabular}

Dari persamaan (1) didapat waktu antar kedatangan setiap konsumen dalam satuan detik seperti dijelaskan pada Tabel 2. Tabel 2 menjelaskan hasil konversi jumlah konsumen menjadi frekuensi kedatangan. Hasil yang didapat secara rata-rata untuk konsumen Pertalite sebesar 20,39 detik dengan standar deviasi 1,13 detik sedangkan untuk konsumen Premium sebesar 40,87 detik dengan standar deviasi 2,95 detik. 
Tabel 2. Data Jarak Waktu Antar Kedatangan Konsumen (detik)

\begin{tabular}{lcc}
\hline Hari & Pertalite & Premium \\
\hline Rata-rata & 20,39 & 40,87 \\
Stdev & 1,13 & 2,95 \\
\hline
\end{tabular}

2. Data Waktu Pelayanan

Pengumpulan data waktu pelayanan diukur dengan menggunakan stopwatch secara langsung di tempat penelitian. Tabel 3 menjelaskan hasil observasi waktu pelayanan di SPBU Pangeran Jayakarta. Berdasarkan observasi, rata-rata waktu pelayanan di SPBU Pangeran Jayakarta adalah 41,59 detik dengan standar deviasi sebesar 6,97 detik.

Tabel 3. Data Waktu Pelayanan (detik)

\begin{tabular}{lc}
\hline \multicolumn{1}{c}{ Jenis } & Waktu Pelayanan \\
\hline Rata-rata & 41,59 \\
Stdev & 6,9667 \\
\hline
\end{tabular}

\subsection{Pengolahan Data}

1. Uji Kecukupan Data

Pengujian kecukupan data adalah pengujian yang dilakukan untuk mengetahui apakah data pengamatan yang telah diambil cukup untuk diolah atau belum. Perhitungan untuk uji kecukupan data diolah dengan menggunakan perangkat lunak Microsoft Excel. Tabel 4 dan Tabel 5 adalah hasil uji kecukupan untuk data jumlah kedatangan konsumen dan data waktu pelayanan secara berurutan. Berdasarkan Tabel 4 dan Tabel 5 dapat dilihat bahwa $N>N^{\prime}$, maka dapat disimpulkan bahwa data jumlah kedatangan konsumen yang digunakan sudah cukup.

Tabel 4. Uji Kecukupan Data Jumlah Kedatangan Konsumen

\begin{tabular}{ccccc}
\hline & $\begin{array}{c}\text { Rata- } \\
\text { rata }\end{array}$ & $\boldsymbol{N}$ & $\boldsymbol{N}$, & Hasil \\
\hline Pertalite & 354,07 & 15 & 1,05 & Data \\
Premium & 177 & 15 & 1,89 & Cukup \\
\hline
\end{tabular}

Tabel 5. Uji Kecukupan Data Waktu Pelayanan

\begin{tabular}{cccc}
\hline Rata-rata (unit) & $\boldsymbol{N}$ & $\boldsymbol{N}^{\prime}$ & Kesimpulan \\
\hline $\mathbf{4 1 , 5 9}$ & 70 & 11,06 & Data Cukup \\
\hline
\end{tabular}

2. Uji Keseragaman Data

Pengujian keseragaman data adalah suatu pengujian yang berguna untuk memastikan bahwa data yang dikumpulkan berasal dari satu sistem yang sama. Tabel 6 dan Tabel 7 adalah hasil pengujian keseragaman data jumlah kedatangan konsumen dan data waktu pelayanan secara berurutan.

Tabel 6. Uji Keseragaman Data Jumlah Kedatangan Konsumen (orang)

\begin{tabular}{lcc}
\hline & Pertalite & Premium \\
\hline Rata-rata & 354,13 & 177,00 \\
BKA & 391,69 & 202,17 \\
BKB & 316,58 & 151,83 \\
Hasil & Data Seragam & Data Seragam \\
\hline
\end{tabular}

Tabel 7. Uji Keseragaman Data Waktu Pelayanan (detik)

\begin{tabular}{cccc}
\hline Rata-rata (unit) & BKA & BKB & Kesimpulan \\
\hline $\mathbf{4 1 , 5 9}$ & 55,53 & 27,66 & $\begin{array}{c}\text { Data } \\
\text { Seragam }\end{array}$ \\
\hline
\end{tabular}

3. Pengujian Distribusi

Pengujian distribusi dilakukan untuk mengetahui distribusi dari data tingkat kedatangan konsumen dan juga waktu pelayanan. Pengujian distribusi menggunakan salah satu dari tools statfit pada ProModel. Tabel 8 adalah hasil pengujian distribusi data waktu kedatangan antar konsumen untuk kedua jenis bahan bakar.

Tabel 8. Pengujian Distribusi Waktu Antar Kedatangan Aktual

\begin{tabular}{lc}
\hline \multicolumn{1}{c}{ Jenis Data } & Distribusi \\
\hline Pertalite & Normal \\
Premium & Normal \\
\hline
\end{tabular}

4. Perancangan Model Simulasi Sistem Aktual Perancangan model simulasi sistem nyata dilakukan dengan menggunakan perangkat lunak ProModel. Elemen-elemen yang digunakan dalam perancangan model ini adalah sebagai berikut:

a. Entity Flow Diagram

Gambar 1 menjelaskan aliran kegiatan dari sistem di SPBU Pangeran Jayakarta. Konsumen Pertalite dan Premium masing-masing memiliki aliran yang relatif sama dari kedatangan hingga keluar dari sistem setelah dilayani. 


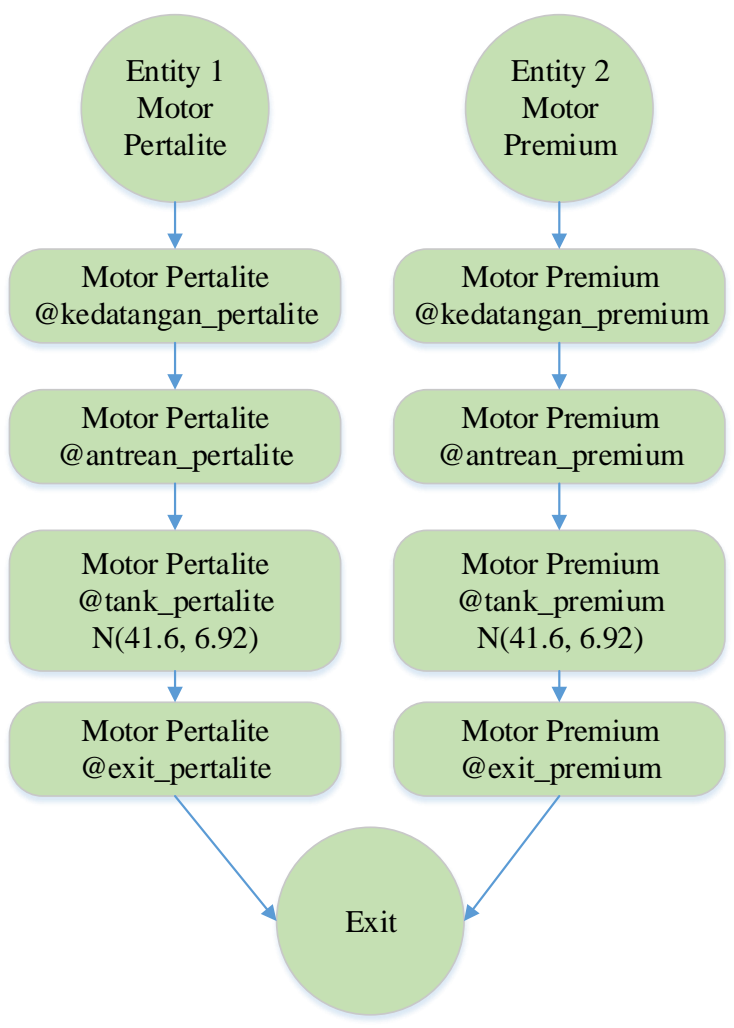

Gambar 1. Entity Flow Diagram

b. Layout Promodel

Gambar 2 adalah layout dari sistem aktual SPBU Pangeran Jayakarta. Berdasarkan Gambar 2, dapat dilihat bahwa layout yang digunakan pada sistem aktual dari SPBU Jayakarta menggunakan 2 lini antrean untuk konsumen Pertalite dan 1 lini antrean untuk konsumen Premium. Masing-masing lini antrean memiliki 1 tangki pengisian bahan bakar sesuai jenis dari antreannya.

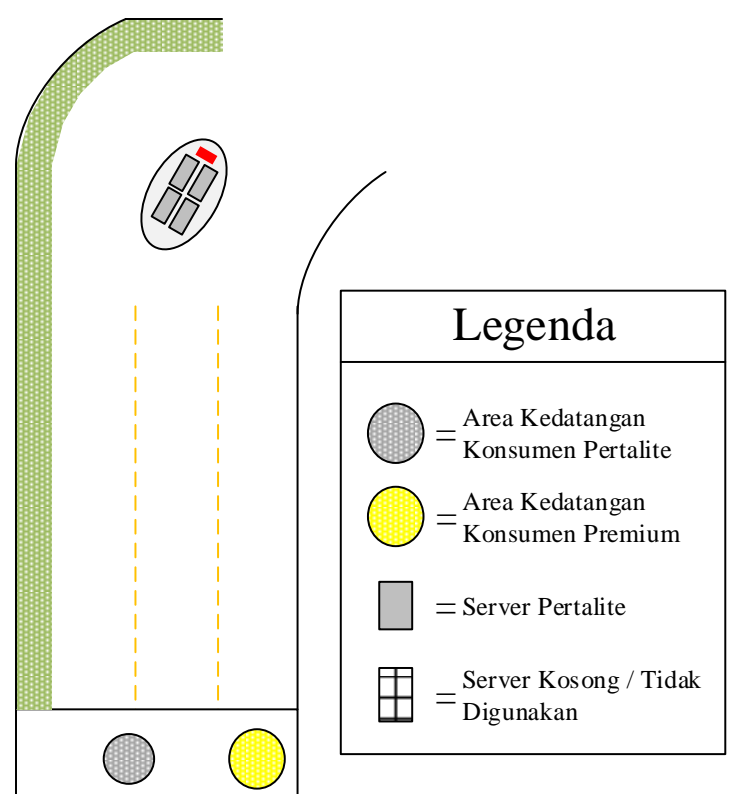

Gambar 2. Layout ProModel

c. Entity

Entity yang digunakan adalah "motor_pertalite" sebagai kode konsumen Pertalite dan "motor_premium" sebagai kode konsumen Premium.

d. Location

Location yang digunakan dalam perancangan model terdiri dari titik kedatangan, lini antrean, tank pengisian dan titik keluar (exit). Dalam penelitian ini lokasi "tank_pertalite" berjumlah dua, sedangkan lokasi "tank_premium" berjumlah satu.

e. Processing

Penentuan aliran proses mengikuti entity flow diagram yang berfungsi untuk menjelaskan aliran proses atau kegiatan dalam sistem dari titik kedatangan hingga titik keluar.

f. Arrival

Arrival yang digunakan untuk konsumen Pertalite adalah pada titik kedatangan Pertalite sedangkan untuk konsumen Premium adalah pada titik kedatangan Premium dengan Qty each sebesar 1(satu), First time sebesar 0 (nol), Occurence sebesar INF (infinity) dan frequency mengikuti hasil pengujian distribusi dari masing-masing jenis bahan bakar. 
5. Verifikasi dan Validasi Model

Verifikasi model simulasi dilakukan dengan memeriksa kesalahan atau ketidaksesuaian process logic melalui menu debug pada ProModel (simulation->run->option$>$ debug) dimana pada model simulasi sistem antrean pada SPBU yang dirancang tidak ditemukan ketidaksesuaian. Validasi model dilakukan dengan pengujian statistik untuk menguji perbedaan rata-rata dan varian pada dua sampel independen. Pengujian rata-rata menggunakan independent sample t-test dan pengujian varian menggunakan one-way ANOVA yang dilakukan dengan perangkat lunak SPSS. Tabel 9 adalah hasil dari independent sample t-test untuk data tingkat kedatangan konsumen. Tabel 9 merupakan output yang didapat dari perangkat lunak SPSS menunjukkan bahwa Sig.(2-tailed) memberikan nilai sebesar 0,823 dan 0,919 untuk jenis bahan bakar Pertalite dan Premium secara berturut-turut. Nilai tersebut lebih besar dari $\alpha$ yang digunakan yaitu 0,05 . Oleh karena itu, dapat disimpulkan bahwa sistem aktual dan model simulasi yang dirancang tidak memiliki perbedaan ratarata.

Tabel 10 adalah hasil dari one-way ANOVA untuk data tingkat kedatangan konsumen. Tabel 10. merupakan output yang didapat dari perangkat lunak SPSS menunjukkan bahwa nilai Sig memberikan nilai sebesar 0,907 untuk jenis bahan bakar Pertalite dan 0,817 untuk jenis bahan bakar Premium dimana nilai tersebut lebih besar dari $\alpha$ yang digunakan yaitu 0,05. Maka dapat disimpulkan bahwa sistem aktual dan model simulasi yang dirancang tidak memiliki perbedaan variansi.

Tabel 9. Independent Sample t-test

\begin{tabular}{cc}
\hline Jenis Data & Sig. (2-tailed) \\
\hline Kedatangan Pertalite & 0,823 \\
Kedatangan Premium & 0,919 \\
\hline
\end{tabular}

Tabel 10. One-Way ANOVA

$\begin{array}{lc}\text { Jenis Data } & \text { Sig. (2-tailed) } \\ 0,907\end{array}$

Kedatangan Premium $\quad 0,817$

Setelah model yang dirancang telah diverifikasi dan divalidasi, model yang dirancang dapat dilakukan analisis terhadap sistem tersebut. Analisis dari model sistem aktual didapatkan dengan run hours selama 2 jam dengan 30 kali replikasi. Tabel 11 adalah hasil rata-rata dari 30 kali replikasi simulasi sistem actual. Berdasarkan Tabel 11, dapat dilihat bahwa jumlah antrean Pertalite dan Premium melebihi standar yang ditetapkan dari SPBU yaitu sebanyak 10 antrean, maka dari itu dibutuhkan tindakan perbaikan dari sistem agar rata-rata jumlah antrean dapat diminimalkan.

Tabel 11. Hasil Simulasi Aktual

\begin{tabular}{lcc}
\hline & Pertalite & Premium \\
\hline Pelayanan & 353,70 & 177,23 \\
Konsumen Tidak & 46,40 & 34,00 \\
Terlayani & 11,32 & 11,67 \\
Rata-rata Antrean & & \\
\hline
\end{tabular}

Langkah-langkah tindakan perbaikan yang akan dilakukan dapat dilakukan dengan cara seperti yang dijelaskan pada Gambar 3 . Berdasarkan Langkah modifikasi sistem antrean tidak dapat digunakan dikarenakan jumlah antrean pada server Premium yang dirubah menjadi multi-product server akan tetap mengantre. Maka dari itu tindakan perbaikan pertama adalah menggunakan asumsi penurunan waktu pelayanan sebesar $10 \%$. Hasil yang didapat ditampilkan pada Tabel 12. Berdasarkan Tabel 12, rata-rata antrean lebih kecil dari 10 konsumen. Maka dari itu dapat disimpulkan bahwa untuk menyelesaikan permasalahan pada sistem aktual adalah dengan cara mengurangi waktu pelayanan sebesar $10 \%$.

Tabel 12. Perbaikan Sistem Aktual dengan Penurunan Waktu Pelayanan 10\% (orang)

\begin{tabular}{lcc}
\hline & Pertalite & Premium \\
\hline Pelayanan & 336,87 & 168,70 \\
Konsumen Tidak & 16,73 & 7,77 \\
Terlayani & 4,02 & 3,81 \\
Rata-rata Antrean & & \\
\hline
\end{tabular}




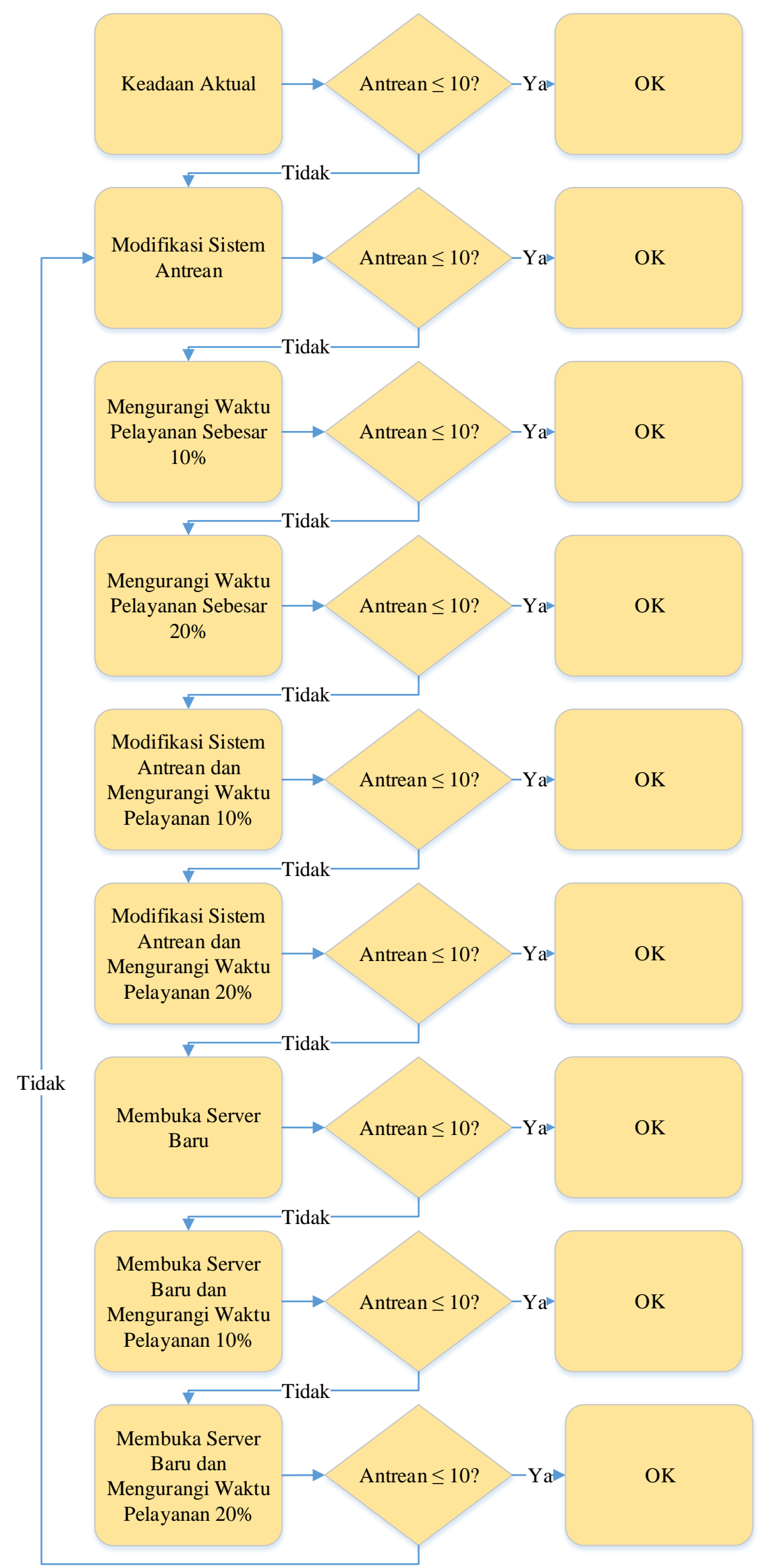

Gambar 3. Flowchart Perbaikan 
6. Perancangan Model Skenario

Perancangan model skenario dibuat berdasarkan regulasi pemerintah yang berencana untuk memberikan kuota untuk bahan bakar jenis premium berdampak kepada perpindahan konsumen dari Premium ke Pertalite. Model skenario yang digunakan dalam penelitian ini adalah terjadi perpindahan jumlah konsumen dari Premium dan Pertalite. Skenario pertama adalah perpindahan 30\% konsumen Premium ke Pertalite, skenario kedua adalah perpindahan 60\% konsumen Premium ke Pertalite, dan skenario ketiga adalah perpindahan $100 \%$ konsumen Premium ke Pertalite.

a. Skenario I

Berdasarkan Tabel 13, perpindahan 30\% konsumen Premium ke Pertalite menghasilkan rata-rata jumlah konsumen Pertalite menjadi 407,17 orang dan konsumen Premium sebesar 123,9 orang.

Tabel 13. Data Kedatangan Konsumen Skenario I (orang)

\begin{tabular}{lcc}
\hline \multicolumn{1}{r}{ Data } & Pertalite & Premium \\
\hline Rata-rata & 407,17 & 123,90 \\
Stdev & 18,90 & 8,81 \\
\hline
\end{tabular}

Tabel 14. Data Jarak Waktu antar Kedatangan Skenario I (detik)

\begin{tabular}{rcc}
\hline Data & Pertalite & Premium \\
\hline Rata-rata & 17,72 & 58,39 \\
Stdev & 0,85 & 4,21 \\
\hline
\end{tabular}

Dari Tabel 13, data jumlah konsumen dikonversi menjadi jarak waktu antar kedatangan menggunakan rumus yang telah dijelaskan sebelumnya. Tabel 14 adalah hasil perhitungan jarak waktu antar kedatangan untuk skenario I. Berdasarkan Tabel 14 dapat dilihat bahwa rata-rata jarak waktu antar kedatangan untuk konsumen Pertalite adalah 17,72 detik dan untuk konsumen Premium adalah 58,39 detik.

Langkah berikutnya adalah dengan melakukan pengujian distribusi dari data jarak waktu antar kedatangan. Tabel 15 adalah hasil yang didapat dari menu statfit pada perangkat lunak ProModel.
Tabel 15. Pengujian Distribusi Waktu Antar Kedatangan Skenario I

\begin{tabular}{lc}
\hline \multicolumn{1}{c}{ Jenis Data } & Distribusi \\
\hline Pertalite & Normal \\
Premium & Normal \\
\hline
\end{tabular}

Langkah perancangan model pada skenario I diawali dengan langkah memodifikasi sistem antrean dengan merubah server Premium menjadi multiproduct server. Tabel 16 adalah hasil dari modifikasi sistem antrean.

Tabel 16. Modifikasi Sistem Skenario I (orang)

\begin{tabular}{lcc}
\hline & Pertalite & Premium \\
\hline Pelayanan & 353,07 & 107,33 \\
Konsumen Tidak & 54,26 & 16,50 \\
Terlayani & 11,60 & 11,49 \\
Rata-rata Antrean & & \\
\hline
\end{tabular}

Berdasarkan Tabel 16, rata-rata jumlah antrean lebih besar dari 10 konsumen. Maka dari itu, langkah perbaikan selanjutnya adalah dengan menggunakan asumsi penurunan waktu pelayanan sebesar $10 \%$. Hasil yang didapat dijelaskan pada Tabel 17.

Tabel 17. Penurunan Waktu Pelayanan 10\% Skenario I (orang)

\begin{tabular}{lcc}
\hline & Pertalite & Premium \\
\hline Pelayanan & 337,63 & 122,67 \\
Konsumen Tidak & 69,89 & 1,16 \\
Terlayani & 17,23 & 0,43 \\
Rata-rata Antrean & &
\end{tabular}

Berdasarkan Tabel 17, rata-rata jumlah antrean lebih besar dari 10 konsumen. Maka dari itu, langkah perbaikan selanjutnya adalah dengan menggunakan asumsi penurunan waktu pelayanan sebesar 20\%. Hasil yang didapat ditampilkan pada Tabel 18.

Tabel 18. Penurunan Waktu Pelayanan 20\% Skenario I (orang)

\begin{tabular}{lcc}
\hline & Pertalite & Premium \\
\hline Pelayanan & 373,73 & 122,80 \\
Konsumen Tidak & 33,70 & 1,07 \\
Terlayani & 8,40 & 0,43 \\
Rata-rata Antrean & & \\
\hline
\end{tabular}

Berdasarkan Tabel 18, rata-rata antrean lebih kecil dari 10 konsumen. Maka dari 
itu dapat disimpulkan bahwa untuk menyelesaikan permasalahan pada skenario I adalah dengan cara mengurangi waktu pelayanan sebesar $20 \%$.

b. Skenario II

Berdasarkan Tabel 19, perpindahan $60 \%$ konsumen Premium ke Pertalite menghasilkan rata-rata jumlah konsumen Pertalite menjadi 481,51 orang dan konsumen Premium sebesar 70,8 orang.

Tabel 19. Data Kedatangan Konsumen Skenario II (orang)

\begin{tabular}{lcc}
\hline \multicolumn{1}{c}{ Data } & Pertalite & Premium \\
\hline Rata-rata & 481,51 & 70,80 \\
Stdev & 20,09 & 5,03
\end{tabular}

Tabel 20. Data Jarak Waktu antar Kedatangan Skenario II (detik)

\begin{tabular}{lcc}
\hline \multicolumn{1}{c}{ Data } & Pertalite & Premium \\
\hline Rata-rata & 14,98 & 102,18 \\
Stdev & 0,64 & 7,36 \\
\hline
\end{tabular}

Dari Tabel 19, data jumlah konsumen dikonversi menjadi jarak waktu antar kedatangan menggunakan rumus yang telah dijelaskan sebelumnya. Tabel 20 adalah hasil perhitungan jarak waktu antar kedatangan untuk skenario II. Berdasarkan Tabel 20, dapat dilihat bahwa rata-rata jarak waktu antar kedatangan untuk konsumen Pertalite adalah 14,98 detik dan untuk konsumen Premium adalah 102,18 detik.

Langkah berikutnya adalah dengan melakukan pengujian distribusi dari data jarak waktu antar kedatangan. Tabel 21 adalah hasil yang didapat dari menu statfit pada perangkat lunak ProModel.

Tabel 21. Pengujian Distribusi Waktu Antar Kedatangan Skenario II

\begin{tabular}{lc}
\hline \multicolumn{1}{c}{ Jenis Data } & Distribusi \\
\hline Pertalite & Normal \\
Premium & Normal \\
\hline
\end{tabular}

Langkah perancangan model pada skenario II diawali dengan langkah memodifikasi sistem antrean dengan merubah server Premium menjadi multiproduct server. Tabel 22 adalah hasil dari modifikasi sistem antrean.
Tabel 22. Modifikasi Sistem Skenario II (orang)

\begin{tabular}{lcc} 
& Pertalite & Premium \\
\hline Pelayanan & 391,70 & 66,90 \\
Konsumen Tidak & 93,50 & 15,50 \\
Terlayani & 17,20 & 17,16 \\
Rata-rata Antrean & &
\end{tabular}

Berdasarkan Tabel 22, rata-rata jumlah antrean lebih besar dari 10 konsumen. Maka dari itu, langkah perbaikan selanjutnya adalah dengan menggunakan asumsi penurunan waktu pelayanan sebesar 10\%. Hasil yang didapat ditunjukkan pada Tabel 23.

Tabel 23. Penurunan Waktu Pelayanan 10\%

\begin{tabular}{lcc}
\multicolumn{3}{c}{ Skenario II (orang) } \\
\hline & Pertalite & Premium \\
\hline Pelayanan & 336,50 & 70,43 \\
Konsumen Tidak & 144,43 & 0,67 \\
Terlayani & 35,79 & 0,25 \\
Rata-rata Antrean &
\end{tabular}

Berdasarkan Tabel 23, rata-rata jumlah antrean lebih besar dari 10 konsumen. Maka dari itu, langkah perbaikan selanjutnya adalah dengan menggunakan asumsi penurunan waktu pelayanan sebesar 20\%. Hasil yang didapat dijelaskan pada Tabel 24.

Tabel 24. Penurunan Waktu Pelayanan 20\%

\begin{tabular}{lcc}
\multicolumn{3}{c}{ Skenario II (orang) } \\
\hline & Pertalite & Premium \\
\hline Pelayanan & 374,10 & 70,43 \\
Konsumen Tidak & 106,50 & 0,58 \\
$\begin{array}{l}\text { Terlayani } \\
\text { Rata-rata Antrean }\end{array}$ & 26,42 & 0,25 \\
\hline
\end{tabular}

Berdasarkan Tabel 24, rata-rata jumlah antrean lebih besar dari 10 konsumen. Maka dari itu, langkah perbaikan selanjutnya adalah dengan menggabungkan langkah modifikasi sistem antrean dan asumsi penurunan waktu pelayanan sebesar $10 \%$. Hasil yang didapat ditampilkan pada Tabel 25. 
Tabel 25. Kombinasi Modifikasi Sistem dan Penurunan Waktu Pelayanan 10\% Skenario II (orang)

\begin{tabular}{lcc}
\hline & Pertalite & Premium \\
\hline Pelayanan & 440,9 & 65,23 \\
Konsumen Tidak & 39,5 & 5,87 \\
Terlayani & 7,6 & 7,28 \\
Rata-rata Antrean & & \\
\hline
\end{tabular}

Berdasarkan Tabel 25, rata-rata antrean lebih kecil dari 10 konsumen. Maka dari itu dapat disimpulkan bahwa untuk menyelesaikan permasalahan pada skenario II adalah dengan cara memodifikasi sistem antrean dengan menggunakan multi-product server serta mengurangi waktu pelayanan sebesar $10 \%$.

c. Skenario III

Berdasarkan Tabel 26, perpindahan 100\% konsumen Premium ke Pertalite menghasilkan rata-rata jumlah konsumen Pertalite menjadi 658,51 orang tanpa konsumen Premium.

Tabel 26. Data Kedatangan Konsumen dengan Perpindahan $100 \%$ (orang)

\begin{tabular}{lc}
\hline \multicolumn{1}{c}{ Data } & Pertalite \\
\hline Rata-rata & 658,51 \\
Stdev & 27,20 \\
\hline
\end{tabular}

Tabel 27. Data Jarak Waktu antar Kedatangan Skenario III (detik)

\begin{tabular}{lc}
\hline \multicolumn{1}{c}{ Data } & Pertalite \\
\hline Rata-rata & 10,95 \\
Stdev & 0,46 \\
\hline
\end{tabular}

Selanjutnya, data jumlah konsumen dikonversi menjadi jarak waktu antar kedatangan menggunakan rumus yang telah dijelaskan sebelumnya. Tabel 27 adalah hasil perhitungan jarak waktu antar kedatangan untuk skenario III.

Berdasarkan Tabel 27, dapat dilihat bahwa rata-rata jarak waktu antar kedatangan untuk konsumen Pertalite adalah 10,95 detik. Langkah berikutnya adalah dengan melakukan pengujian distribusi dari data jarak waktu antar kedatangan. Tabel 28 adalah hasil yang didapat dari menu statfit pada perangkat lunak ProModel.
Tabel 28. Pengujian Distribusi Waktu Antar Kedatangan Skenario III

\begin{tabular}{lc}
\hline \multicolumn{1}{c}{ Jenis Data } & Distribusi \\
\hline Pertalite & Normal \\
Premium & Normal \\
\hline
\end{tabular}

Langkah perancangan model pada skenario III diawali dengan analisis dengan menggunakan 3 buah server Pertalite. Tabel 29 adalah hasil dari keadaan awal dengan 3 server Pertalite.

Tabel 29. Kondisi Awal Skenario III dengan 3 Server Pertalite (orang)

\begin{tabular}{lc}
\hline & Pertalite \\
\hline Pelayanan & 459,90 \\
Konsumen Tidak Terlayani & 195,43 \\
Rata-rata Antrean & 32,34 \\
\hline
\end{tabular}

Berdasarkan Tabel 29, rata-rata jumlah antrean lebih besar dari 10 konsumen. Maka dari itu, langkah perbaikan selanjutnya adalah dengan menggunakan asumsi penurunan waktu pelayanan sebesar $10 \%$. Hasil yang didapat dijelaskan pada Tabel 30.

Tabel 30. Penurunan Waktu Pelayanan 10\% Skenario III (orang)

\begin{tabular}{lc}
\hline & Pertalite \\
\hline Pelayanan & 506,20 \\
Konsumen Tidak Terlayani & 149,00 \\
Rata-rata Antrean & 24,58 \\
\hline
\end{tabular}

Berdasarkan Tabel 30, rata-rata jumlah antrean lebih besar dari 10 konsumen. Maka dari itu, langkah perbaikan selanjutnya adalah dengan menggunakan asumsi penurunan waktu pelayanan sebesar 20\%. Hasil yang didapat ditampilkan pada Tabel 31.

Tabel 31. Penurunan Waktu Pelayanan 20\% Skenario III (orang)

\begin{tabular}{lc}
\hline & Pertalite \\
\hline Pelayanan & 560,17 \\
Konsumen Tidak Terlayani & 95,13 \\
Rata-rata Antrean & 15,76 \\
\hline
\end{tabular}

Berdasarkan Tabel 31, rata-rata jumlah antrean lebih besar dari 10 konsumen. Maka dari itu, langkah perbaikan selanjutnya adalah dengan membuka server baru dikarenakan langkah 
modifikasi antrean tidak bisa dilakukan karena hanya memiliki produk Pertalite. Hasil yang didapat ditunjukkan pada Tabel 32. Berdasarkan Tabel 32, rata-rata antrean lebih kecil dari 10 konsumen. Maka dari itu dapat disimpulkan bahwa untuk menyelesaikan permasalahan pada skenario III adalah dengan cara membuka server baru.

Tabel 32. Membuka Server Baru Skenario III (orang)

\begin{tabular}{lc}
\hline & Pertalite \\
\hline Pelayanan & 612,77 \\
Konsumen Tidak Terlayani & 43,13 \\
Rata-rata Antrean & 5,34 \\
\hline
\end{tabular}

\section{SIMPULAN}

Model sistem aktual yang terjadi pada SPBU Pangeran Jayakarta untuk kendaraan roda dua dengan jenis bahan bakar Premium dan Pertalite pada hari Senin sampai Jumat pada pukul 16.00-18.00 menggunakan 2 server Pertalite dan 1 server Premium dengan rata-rata waktu pelayanan 41,59 detik dan standar deviasi 6,97 detik.

Kinerja model sistem aktual yang terjadi pada SPBU Pangeran Jayakarta yang dianalisis dalam waktu 2 jam menghasilkan jumlah pelayanan sebanyak 354 konsumen Pertalite dan 177 konsumen Premium. Jumlah konsumen yang tidak terlayani untuk konsumen Pertalite sebanyak 47 orang dan untuk konsumen Premium sebanyak 24 orang. Rata-rata antrean server Pertalite sebanyak 11 orang, dan rata-rata antrean server Premium sebanyak 12 orang. Tindakan perbaikan perlu dilakukan karena jumlah antrean yang melebihi standar yang ditetapkan SPBU sebanyak 10 antrean dengan mengurangi waktu pelayanan sebesar 10\% menghasilkan jumlah pelayanan sebanyak 337 konsumen Pertalite dan 169 konsumen Premium. Jumlah konsumen yang tidak terlayani untuk konsumen Pertalite sebanyak 17 orang dan untuk konsumen Premium sebanyak 8 orang. Rata-rata antrean server Pertalite sebanyak 4 orang, dan rata-rata antrean server Premium sebanyak 4 orang.

Model sistem yang diusulkan dengan skenario pertama yaitu perpindahan konsumen dari Premium ke Pertalite sebesar 30\% adalah dengan cara mengurangi waktu pelayanan sebesar 20\% menghasilkan jumlah pelayanan sebanyak 374 konsumen Pertalite dan 123 konsumen Premium. Jumlah konsumen yang tidak terlayani untuk konsumen Pertalite sebanyak 34 orang dan untuk konsumen Premium sebanyak 1 orang. Rata-rata antrean server Pertalite sebanyak 8 orang, dan rata-rata antrean server Premium sebanyak 1 orang.

Model sistem yang diusulkan dengan skenario kedua yaitu perpindahan konsumen dari Premium ke Pertalite sebesar $60 \%$ adalah dengan cara memodifikasi sistem antrean dengan menggunakan multi-product server serta mengurangi waktu pelayanan sebesar $10 \%$ menghasilkan jumlah pelayanan sebanyak 441 konsumen Pertalite dan 65 konsumen Premium. Jumlah konsumen yang tidak terlayani untuk konsumen Pertalite sebanyak 40 orang dan untuk konsumen Premium sebanyak 6 orang. Rata-rata antrean server Pertalite sebanyak 8 orang, dan rata-rata antrean server Premium sebanyak 7 orang.

Model sistem yang diusulkan dengan skenario ketiga yaitu perpindahan konsumen dari Premium ke Pertalite sebesar 100\% adalah dengan cara membuka satu buah server Pertalite menghasilkan jumlah pelayanan sebanyak 613 konsumen Pertalite. Jumlah konsumen yang tidak terlayani untuk konsumen Pertalite sebanyak 43 orang. Rata-rata antrean server Pertalite sebanyak 5 orang.

\section{DAFTAR PUSTAKA}

Adipraesetya, R., Sukmaaji, A. dan Taufik, V. M. (2014) "Penentuan Lokasi Stasiun Pengisian Bahan Bakar Umum (SPBU) Baru Dengan Menggunakan Metode ELECTRE III (Studi Kasus PT. Pertamina Surabaya)," Jurnal Sistem Informasi, 3(1), hal. 132-138.

Badan Pusat Statistik Provinsi DKI Jakarta (2015) Statistik Daerah Provinsi DKI Jakarta 2015. Tersedia pada: https://jakarta.bps.go.id/publication/2015 /11/02/5fe72e0f3b10eb76d7d2a9df/statis tik-daerah-provinsi-dki-jakarta2015.html.

Nsude, F. I., Elem-Uche, O. dan Uwabunkonye, B. (2017) "Analysis of Multiple-queue Multiple-server Queuing System: A Case Study of First Bank NIG. PLC, Afikpo Branch," International Journal of Scientific \& Engineering Research, 8(1), hal. 1700-1709. 